\title{
Technological pedagogical knowledge self-efficacy and continuance intention of Philippine teachers in remote education amid COVID-19 crisis
}

\author{
Michael B. Cahapay ${ }^{1}$ and Jeorge Louie D. Anoba ${ }^{2}$ \\ ${ }^{1}$ Mindanao State University, College of Education, Philippines (ORCID: 0000-0002-0588-0022) \\ ${ }^{2}$ City Schools Division of Koronadal, Department of Education, Philippines (ORCID: 0000-0002-6907-1558)
}

\begin{abstract}
With the sudden and forced change to various modalities of remote education amid the COVID-19 crisis, the technological pedagogical knowledge (TPK) self-efficacy and continuance intention of teachers demand an investigation. This article aimed to assess the TPK self-efficacy and continuance intention of teachers in remote education amid the COVID-19 crisis. Employing a quantitative correlational research design, it involved a randomly selected sample of $1065 \mathrm{~K}$ to 12 teachers from Mindanao, Philippines. Two psychometrically tested scales were used to gather the needed data. The analyses were performed using descriptive and inferential statistics. The result indicated that the teachers have high levels of TPK selfefficacy and continuance intention. It further revealed that TPK self-efficacy significantly differed across age, gender, marital status, monthly income, educational attainment, and teaching experience, and continuance intention across age, monthly income, and teaching position. Lastly, the results uncovered a significant positive relationship between TPK self-efficacy and continuance intention of teachers. This study provides implications on the sustained technology use in Philippine education. The theoretical and practical contributions are also discussed in the study.
\end{abstract}

Keywords: Technological pedagogical knowledge; Self-efficacy; Continuance intention; Remote education; Educational technology; COVID-19 crisis

Article History: Submitted 13 February 2021; Revised 28 June 2021; Published online 12 July 2021

\section{Introduction}

Education is one of the essential sectors most devastated by the detrimental effects of the COVID19 crisis. The International Association of Universities (2020) initially reported that more than a billion students around the globe were affected by school interruptions and the crisis continues to distress especially the vulnerable segment of learners. The World Bank (2020) has firmly cautioned authorities about the consequences of decreased school attendance such as the permanent deprivation of knowledge and the bleak future financial prospect of the learners. Some scholars project that the steep learning curve will haunt learners in the more years to come. Amid these grim realities, the United Nations (2021) has recently encouraged countries to look at the brighter

\section{Address of Corresponding Author}

Michael B. Cahapay, PhD College of Education, Mindanao State University, General Santos City, 9500, Philippines.

$\triangle$ mbcahapay@up.edu.ph

How to cite: Cahapay, M. B. \& Anoba, J. L. D. (2021). Technological pedagogical knowledge self-efficacy and continuance intention of Philippine teachers in remote education amid COVID-19 crisis. Journal of Pedagogical Research, 5(3), 68-79. https://doi.org/10.33902/JPR.2021370614 
side of the situation, redirecting them to take the disruption as a rather good opportunity to renew education systems.

With the current realities, technology has been dubbed by scholars as the "holy grail" that will solve the educational implementation issues brought by the COVID-19 (Obana, 2020 as cited in Anoba \& Cahapay, 2020). With teachers and learners barred at homes, it has enabled educational continuity and recovery. Amid the continual crisis, technology under ideal conditions has promoted flexibility in the place and time to study, accessibility of different teaching and learning resources, personalized ways of teaching and learning, and readiness for future digital demands. The scale of teaching and learning required for effective educational continuity seemed to mostly rely on adopting and integrating technology into the practice. The COVID-19 crisis has indeed motivated schools and education to engage in extensive technological transformation (Iivari et al., 2020).

While the extensive school interruptions occurred in a period that has generally been fashioned by fast technological transformation, however, it is not always the case for developing countries like the Philippines. The use of technology in education has been a perennial issue in the country. Dotong et al. (2016) previously reported that barriers to educational technology integration in most developing countries including the Philippines are inadequate financial assistance, structural capability, human resources, management support, as well as behavioral factors. This reality is specifically affirmed in the ground today. Some scholars (e.g. Alea et al., 2020; Mallillin et al., 2020) reveal modest readiness of schools in implementing various modalities of remote education. Many schools are situated in a kind of unknown experimental predicament, trying which alternative works better in a given situation. Drawing insights from case studies, Luz (2020) suggested that the experimentation with remote modalities of education will have to be steered by teachers who are most proximally connected to the learners on the ground.

Considering the crucial role of the teachers, two personal factors that several studies put forward as instrumental toward the sustained use of technologies in the different modalities of remote teaching and learning are self-efficacy and continuance intention (Bai et al., 2019; Chiu \& Wang, 2008; Hayashi et al., 2004; Ismail et al., 2012; Lai et al., 2018; Lazar et al., 2020; Tang et al., 2014; Wang et al., 2019). Most of the reviewed studies above investigate the relationship between self-efficacy and continuance intention as part of some larger frameworks with several variables on a complex path of relationships. This present study takes a more granular approach by specifically focusing on the difference in the TPK self-efficacy and continuance intention across selected teacher characteristics and then testing the relationship between these two constructs.

Discussing these two constructs, Lazar et al. (2020) suggested the construct of TPK self-efficacy in their recent study to embrace a host of numerous terms used by scholars in the field such as technology integration self-efficacy (e.g. see Durak, 2019; Johnson, 2020) and information and communication technologies self-efficacy (e.g. Dong et al., 2020; Hatlevick et al., 2018; Rohatgi et al., 2016). TPK self-efficacy can be defined as the perceived competence of an individual in understanding how technology uses affects teaching and learning (Kiray, 2016). On the other hand, continuance intention refers to the decision of individuals to remain using particular tools (Han et al., 2018), which in this case, are technological tools in remote teaching. Linking these two main constructs of interest in this study, Roca and Gagne (2008) affirmed that self-efficacy is a central factor to understand continuance intention in the workplace.

Within the scope of the current study, it is aimed to assess the TPK self-efficacy and continuance intention of teachers in remote education amid the COVID-19 crisis.

\subsection{Background}

This research theoretically posits the influence of a cognitive factor on continuance intention in a context amid a global emergency. Thus, the chosen theoretical framework of the present study assimilated important elements of motivational issues and job demands caused by a disruptive 
event. Moreover, it extols the significance of understanding the interactions of such a cognitive factor and continuance intention.

Such a cognitive factor is operationalized in this study as TPK self-efficacy, the perceived ability of the teachers in understanding how technology shapes instructional development (Kiray, 2016). It is based on the Self Determination Theory (SDT) proposed by Deci and Ryan (1980). It is a theory of human motivation that is concerned with the type of motivation believed to underlie the decisions that people make without outside influence. This theory is considered a major reference in studies on digital technology acceptance (Lazar et al., 2020).

On the other hand, the continuance intention is the decision of individuals to remain using particular tools (Han et al., 2018). It is based on the Technology Acceptance Model (TAM) developed by Davis (1989). It is an information systems theory that demonstrates how users come to use technology. It posits behavioral intention as a factor that leads people to use the technology. Moreover, this model is a multidimensional paradigm that demonstrates the results of interactions between cognitive factors in complex learning situations (Lazar et al., 2020).

The general construct of self-efficacy which is based on SDT is a common predictor used in TAM which includes the continuance intention (Lazar et al., 2020). Thus, in this study, the researchers cogently conceptualized the relationship between TPK self-efficacy and continuance intention of teachers in remote education amid the COVID-19 crisis. It is hypothesized that TPK self-efficacy is associated with continuance intention. It is anticipated that a positive and direct significant relationship exists between these two variables such that if TPK self-efficacy is high, the continuance intention of the teachers will also be high.

Considering this issue, current paper aimed to determine the TPK self-efficacy and continuance intention of teachers in remote education amid the COVID-19 crisis. Specifically, it sought to address the following questions:

1. What are the levels of TPK self-efficacy and continuance intention of the teachers in remote education?

2. Is there a significant difference in the TPK self-efficacy and continuance intention of the teachers in remote education?

3. Is there a significant relationship between the TPK self-efficacy and continuance intention of the teachers in remote education?

Addressing these questions will contribute to the literature from different perspectives.. It is important to understand TPK self-efficacy and continuance intention of the teachers in the context of emergency remote education as they are key factors in intuiting the cognitive choice of the teachers to use technologies in education. Despite these realities, however, there is limited attention that has been noted in this particular area of research interest. A review of recent scholarly works shows an emerging body of studies on student self-efficacy and continuance intention in online learning (e.g. Chauhan et al., 2021; Cicha et al., 2021; Cui, 2021; Lin, 2021; Mo et al., 2021; Wang et al., 2021). There is limited interest in teacher TPK self-efficacy (e.g. Ma et al., 2021; Santi et al., 2020; Yang, 2021) and continuance intention (e.g. Nikou, 2021), and the association between these two variables has not been explored. Thus, set in emergency remote education amid the COVID-19 crisis, this current study hopes to draw relevant, appropriate, and responsive measures regarding the sustained use of technologies among the teachers in the educational context of a developing country.

\section{Method}

Guided by the research goal, this section presents the research design, respondents, instrumentation, data collection, and data analysis of this study. They are discussed as follows.

\subsection{Research Design}

This research uses a quantitative approach specifically employing a correlational research design. According to Sousa et al. (2007), correlational research design involves an organized investigation of the nature of relationships between two or more variables. It also intends to uncover if there are 
differences in the characteristics of a sample whether or not its respondents have been exposed to the phenomenon of interest in the natural setting (Lau, 2017). Given the stated purpose of this research, the correlational research design is deemed appropriate.

\subsection{Participants}

The participants of this study are $1065 \mathrm{~K}$ to 12 teachers employed in various government and private schools in Mindanao, Philippines. They were selected using a mainly random sampling technique. It is a sampling technique in which the respondents are selected by chance, but with a known possibility of selection (Lavrakas, 2008). The respondents in this study were included regardless of age, gender, marital status, monthly income, and educational attainment.

Table 1

Demographic characteristics

\begin{tabular}{llcc}
\hline Characteristics & & $N$ & $\%$ \\
\hline Age & 34 years old and below & 592 & 55.6 \\
\cline { 2 - 4 } & 35 to 44 years old & 264 & 24.8 \\
\cline { 2 - 4 } & 45 years old and above & 209 & 19.6 \\
\hline \multirow{2}{*}{ Gender } & Memale & 851 & 79.9 \\
\cline { 2 - 4 } & Male & 214 & 20.1 \\
\cline { 2 - 4 } Marital Status & Married & 413 & 38.7 \\
\hline Monthly Income & PHP23,000 and below & 652 & 61.2 \\
\cline { 2 - 4 } & PHP24,000 and above & 671 & 63.0 \\
\hline Educational & Undergraduate degree & 394 & 37.0 \\
\cline { 2 - 4 } Attainment & Graduate units or degree & 599 & 66.24 \\
\hline Teaching Position & Teacher I-III & 466 & 43.76 \\
\cline { 2 - 4 } & Master Teacher I-II & 1011 & 74.9 \\
\hline Teaching & $0-10$ years & 54 & 16.2 \\
\cline { 2 - 4 } Experience & $11-20$ years & 172 & 9.8 \\
\cline { 2 - 4 } & 21 years and above & 105 & \\
\hline
\end{tabular}

Table 1 shows the summary of the demographic characteristics of the sample of this study. It can be noted that most of the respondents belong to the age bracket of between 34 years old and below, female, earn PHP23,000 and below, with an undergraduate degree, hold Teacher I-III position, and have teaching experience of 0-10 years. It should be noted that teaching position in the context of this study refers to the employment rank of the teacher assigned or gained through various professional qualifications.

\subsection{Instrument}

The survey instrument used in this study was adapted from Lazar et al. (2020). It consisted of three parts: 1.) items requesting for the characteristics of the participants: age, gender, marital status, monthly income, educational attainment, teaching position, and teaching experience; 2.) items asking for the TPK self-efficacy; and 3.) items asking for the continuance intention. Particularly, the items in the last two parts were framed on a scale of one (strongly disagree) to 5 (strongly agree). A strong internal consistency was established for the items, obtaining an overall Cronbach alpha of .949 for TPK self-efficacy and .874 for continuance intention in this study. This is further supported by robust construct validity with item Eigen values ranging from .784 to .860 for TPK self-efficacy and from .831 to .867 for continuance intention respectively. 


\subsection{Data Collection}

The data were collected from January 25 to February 10, 2021, through an online survey using Google Forms. Due to the difficulty of conducting a face-to-face survey because of the continual COVID-19 crisis, an online survey was preferred. Before participating in the survey, the potential respondents were presented to an initial layer of the web questionnaire, explaining the purpose of the research, process of completing the survey, and ethical considerations involved in this study. The names of the respondents were not required as a means to maintain privacy. It was also stressed that participation in the survey is voluntary and no form of incentive is involved. Then, the informed consent was provided in which the respondents have to agree by ticking a box before they could proceed. After securing the informed consent, the respondents were presented to the main survey instrument containing the items on TPK self-efficacy and continuance intention. All the responses were automatically recorded, and the researcher generated the data for analysis.

\subsection{Data Analysis}

The IBM Statistical Package for Social Science version 17 was employed for the data analysis of this study. All assumptions for the use of each statistical tool were confirmed. A preliminary analysis of the data using descriptive statistics provided for the frequency, mean, percentage rate, and standard deviation for all the variables. A series of $t$-test, Analysis of Variance, and Tukey test were further performed to compare the TPK self-efficacy and continuance intention across the demographic characteristics. Finally, Pearson Product Moment Correlation was applied to test the association between the TPK self-efficacy and continuance intention. All tests were done at a 0.05 level of significance.

\section{Results}

This paper primarily sought to assess the TPK self-efficacy and continuance intention of teachers in remote education amid the COVID-19 crisis. The results are as follows.

Table 2

TPK self-efficacy and continuance intention

\begin{tabular}{lccc}
\hline Item & Mean & SD & Interpretation \\
\hline TPK self-efficacy & & & \\
\hline Item 1 & 3.90 & .88 & High level \\
Item 2 & 3.82 & .99 & High level \\
Item 3 & 3.90 & .86 & High level \\
Item 4 & 3.88 & .87 & High level \\
Item 5 & 3.72 & .98 & High level \\
Item 6 & 3.76 & .94 & High level \\
Item 7 & 3.72 & .97 & High level \\
Item 8 & 3.71 & .90 & High level \\
Item 9 & 3.79 & .87 & High level \\
Item 10 & 3.86 & .84 & High level \\
\hline Overall Mean =3.81 & & & \\
\hline Continuance intention & & & High level \\
\hline Item 1 & 3.37 & 1.12 & High level \\
Item 2 & 3.43 & 1.06 & High level \\
Item 3 & 3.47 & 1.03 & High level \\
Item 4 & 3.46 & 1.12 & High level \\
\hline Overall Mean =3.43 & & &
\end{tabular}

Table 2 illustrates the level of TPK self-efficacy in remote education. The outcomes uncovered that the respondents have a high level of TPK self-efficacy in all the items. It can be noted that they 
have the highest level of TPK self-efficacy in terms of designing lessons that can be used in remote learning environments (Item 3; $M=3.90 ; S D=.86$ ); helping students to use remote learning environments effectively (Item $1 ; M=3.90 ; S D=.88$ ); recommending study materials enriched with open educational resources (Item $4 ; M=3.88 ; S D=.87$ ); constructively addressing the challenge of remote teaching (Item 10; $M=3.86 ; S D=.84$ ). Overall, the respondents have high TPK self-efficacy $(M=3.81)$; and using technologies that allow them to interact remotely (Item 2; $M=3.82 ; S D=.99)$. Overall, the teachers demonstrate a high level of TPK self-efficacy. This result points to the favorable perception of the teachers regarding their competence in understanding how technology use affects the instructional process.

Furthermore, in terms of continuance intention, the results found out that the respondents consistently have a high level in all the items. Specifically, in order, they have a high level of continuance intention as regards maintaining future involvement in remote teaching as active as today (Item 3; $M=3.47 ; S D=1.03$ ); increasing the frequency of use of online teaching tools in the future (Item $4 ; M=3.46 ; S D=1.12$ ); encouraging students to use online learning environments in the future (Item 2; $M=3.43 ; S D=1.06$ ); and using online tools for online teaching in the future (Item $1 ; M=3.37 ; S D=1.12$ ). As a whole, the respondents have a high level of continuance intention in remote education. This result implies that the teachers have strong conviction in their decision to remain using technological tools in remote education.

Table 3

Differences in TPK self-efficacy and continuance intention

\begin{tabular}{|c|c|c|c|c|c|c|}
\hline \multirow{2}{*}{ Demographic Characteristics } & \multicolumn{3}{|c|}{ TPK Self-Efficacy } & \multicolumn{3}{|c|}{ Continuance Intention } \\
\hline & $M$ & $t / F$ & $p$-value & $M$ & $t / F$ & $p$-value \\
\hline \multicolumn{7}{|l|}{ Age } \\
\hline 34 years old and below & 3.89 & \multirow{3}{*}{10.727} & \multirow{3}{*}{.000} & 3.48 & \multirow{3}{*}{2.975} & \multirow{3}{*}{.050} \\
\hline 35 to 44 years old & 3.78 & & & 3.31 & & \\
\hline 45 years old and above & 3.61 & & & 3.45 & & \\
\hline \multicolumn{2}{|l|}{ Gender } & \multirow{3}{*}{-2.012} & \multirow{3}{*}{.044} & & \multirow{3}{*}{-1.493} & \multirow{3}{*}{.136} \\
\hline Female & 3.78 & & & 3.41 & & \\
\hline Male & 3.90 & & & 3.52 & & \\
\hline \multicolumn{2}{|l|}{ Marital Status } & \multirow{3}{*}{2.946} & \multirow{3}{*}{.003} & & \multirow{3}{*}{.127} & \multirow{3}{*}{.899} \\
\hline Single & 3.89 & & & 3.44 & & \\
\hline Married & 3.75 & & & 3.43 & & \\
\hline \multicolumn{2}{|l|}{ Monthly Income } & \multirow{3}{*}{.244} & \multirow{3}{*}{.807} & & \multirow{3}{*}{-2.042} & \multirow{3}{*}{.041} \\
\hline PHP23,000 and below & 3.81 & & & 3.39 & & \\
\hline PHP24,000 and above & 3.80 & & & 3.51 & & \\
\hline \multicolumn{2}{|l|}{ Educational Attainment } & \multirow{3}{*}{1.943} & \multirow{3}{*}{.050} & & \multirow{3}{*}{-1.382} & \multirow{3}{*}{.167} \\
\hline Undergraduate degree & 3.84 & & & 3.40 & & \\
\hline Graduate units or degree & 3.76 & & & 3.48 & & \\
\hline \multicolumn{2}{|l|}{ Teaching Position } & \multirow{3}{*}{.492} & \multirow{3}{*}{.624} & & \multirow{3}{*}{-2.019} & \multirow{3}{*}{.048} \\
\hline Teacher I-III & 3.81 & & & 3.42 & & \\
\hline Master Teacher I-II & 3.76 & & & 3.66 & & \\
\hline Teaching Experience & & & & & & \\
\hline $0-10$ years & 3.8615 & & & 3.44 & & \\
\hline 11-20 years & 3.6698 & 8.882 & .000 & 3.39 & .279 & $.75 \%$ \\
\hline 21 years and above & 3.6029 & & & 3.44 & & \\
\hline
\end{tabular}

Table 3 shows the differences in TPK self-efficacy and continuance intention across demographic characteristics. The results revealed that the TPK self-efficacy of the respondents significantly differed across age $(p=.000)$; gender $(p=.044)$; marital status $(p=.003)$; educational 
attainment $(p=.050)$; and teaching experience $(p=.000)$. More specifically, significantly higher TPK self-efficacy were noted in male $(M=3.90)$ than female $(M=3.78)$; single $(M=3.89)$ than married $(M=3.75)$; and with an undergraduate degree $(M=3.84)$ than graduate units or degree $(M=3.75)$. Furthermore, significantly higher levels of TPK self-efficacy were noted between respondent groups of 34 years old and below $(M=3.89)$ and 45 years old and above $(M=3.61)$, and between respondent groups of 35 to 44 years old $(M=3.78)$ and 45 years old and above $(M=3.61)$. Similarly, in teaching experience, significantly higher TPK self-efficacy was obtained between respondent groups of 0-10 years $(M=3.86)$ and 11-20 years $(M=3.67)$, and between respondent groups of $0-10$ years $(M=3.86)$ and 21 years and above $(M=3.60)$.

Moreover, the results disclosed that the continuance intention of the respondents significantly differed across age $(p=.050)$; monthly income $(p=.041)$; and teaching position $(p=.048)$. It was further indicated that significantly higher continuance intention was seen in respondents with a monthly income of PHP23,000 and below $(M=3.39)$ than PHP24,000 and above $(M=3.51)$, and with master teacher I-II position $(M=3.66)$ than with teacher I-III position $(M=3.42)$. When it comes to age, significantly higher continuance intention was found between respondent groups of 34 years old and below $(M=3.48)$ and 35 to 44 years old $(M=3.31)$.

Overall, the trend suggests that high levels of TPK self-efficacy are noted in teachers who are male, single, with an undergraduate degree, 34 years old and below, with 0-10 years teaching experience while high levels of continuance intention in teachers with a monthly income of PHP23,000 and below, master teacher I-II position, and 34 years old and below.

Table 4

Relationship between TPK self-efficacy and continuance intention

\begin{tabular}{lcll}
\hline Correlated Variables & Overall Mean & Description \\
\cline { 1 - 3 } TPK Self-Efficacy & 3.81 & High level
\end{tabular}$\quad \mathrm{r}=.33, \mathrm{p}=0.000$

Table 4 indicates the relationship between TPK self-efficacy and continuance intention. The outcomes of correlation analysis unearthed a significant and positive association between the TPK self-efficacy and continuance intention $(r=.33 ; p=.000)$ of the respondents. This result means that the higher is the TPK self-efficacy, the higher also is the continuance intention. However, it should be noted that the extent of this association is low, suggesting other variables that influence the continuance intention of the respondents.

\section{Discussion}

The main purpose of this study is threefold: to describe the levels of TPK self-efficacy and continuance intention of the teachers; to compare TPK self-efficacy and continuance intention across selected demographic characteristics; and to determine the relationship between the TPK self-efficacy and continuance intention of the teachers. The following is the discussion of the results, as well as the implications, of this study.

First, the result of this paper showed a high level of TPK self-efficacy in the teachers in online teaching amid the COVID-19 crisis. Garnering consistently high mean values on all items, it can be noted that the teachers in this study remain highly efficacious despite the complex situation. The high level of TPK self-efficacy uncovered in this study is comparable with the result of several related studies conducted in the past (e.g. Black, 2019; Horvitz et al., 2015; Robinia, 2008) in the context of online teaching. However, as far as this study is concerned, it is one of the first known papers to attentively describe the TPK self-efficacy of teachers in the context of emergency remote teaching amid a crisis. Most other studies describe the general self-efficacy in the context of online teaching and old normal. Comparatively, this research presents a piece of knowledge as regards the have a high level of TPK self-efficacy of teachers despite the drastically changed educational scenario.

When it comes to the continuance intention of the teachers, the same trend can be said. It was 
found out that the teachers have a high level of continuance intention in online teaching, obtaining consistently high mean scores on all the items. The study of Lazar et al. (2020) and Lai et al. (2018) focused on evaluating the psychometric properties of continuance intention as a larger purpose. Other studies (e.g. Guo et al., 2016; Tang et al., 2014; Wang et al., 2019) measured continuance intention in the context of the remote learning of the students. This study provides initial evidence as regards the level of continuance intention of the teachers in emergency remote teaching. Despite the changed situation, this paper proves the strong commitment of the teachers to remain in remote teaching as much as how teachers desire to remain in online teaching in the old normal times.

Furthermore, as far as this study is concerned, there are no current studies specifically assessing the difference in the TPK self-efficacy and continuance intention of teachers in the context of emergency remote education. Typically, related studies in the field suggest that general selfefficacy significantly differs across demographic characteristics such as age, gender, and experience (Butucha, 2013; Cassidy \& Eachus, 2002; Chu, 2010; Huang, 2013; Klassen \& Chiu, 2010; Penrose et al., 2007; Tweed, 2013). The results of this study add pieces of knowledge about the significant differences in the TPK self-efficacy of teachers across age, gender, marital status, educational attainment, and teaching experience. This result may be used in the field as a basis for developing measures that strategically aim to increase the TPK self-efficacy of particular groups of teachers as found in this study.

On the other hand, available scholarly works provide a blurred glimpse into the difference in general continuance intention across demographic characteristics mentioned above. Reviewing studies on continuance intention in different contexts, Lin et al. (2017) provides a piece of evidence about the role of gender in the relationships between perceived benefits and satisfaction in social virtual world continuance. Jang and Liu (2019) also suggested that differences such as age, gender, and experience can moderate the effects of gratifications on continuance intention in mobile augmented reality. This current study presents more specific evidence on the significant differences in the continuance intention of the teachers in online teaching across age, monthly income, and teaching position. Similarly, this outcome may be considered as a valuable input in formulating further measures that purposefully seek to improve the continuance intention of teachers based on their particular characteristics as revealed in this research.

Lastly, the relationship between self-efficacy and continuance intention has been explored by some scholars in different fields and contexts. For example, Tang et al. (2014) confirmed that perceived efficacy is an influential factor in determining the continuance intention of learners in blog learning. Wang et al. (2019) also proved that computer efficacy significantly predicted continuance intention in e-learning. When it comes to teaching, Lai et al. (2018) discovered that perceived efficacy was shown to critically moderate the continuance intention of the teachers in flipped teaching. On the other hand, the study of Lazar et al. (2020) tested the same variables in the context of online learning amid the COVID-19 crisis. Given the scarcity of research focus specifically testing the relationship between TPK self-efficacy and continuance intention, this paper, the present article contributes to these scholarly works by providing novel piece of evidence in the context of emergency remote education in a developing country. It adds new knowledge within the scholarly discussion of intertwining paths of different variables related to SDT and TAM.

\section{Conclusion}

This research aimed to assess the TPK self-efficacy and continuance intention of teachers in remote education amid the COVID-19 crisis. The results draw several conclusions. First, it was found out that the teachers have high levels of TPK self-efficacy and continuance intention. It was also indicated that TPK self-efficacy significantly differed across age, gender, marital status, monthly income, educational attainment, and teaching experience. On the other hand, continuance intention significantly differed across age, monthly income, and teaching position. Lastly, the 
results established a significant positive relationship between TPK self-efficacy and continuance intention of teachers.

Based on the results, this research draws several implications to theory, practice, and research. First, the generally high levels of TPK self-efficacy and continuance intention offer a positive indication of the sustained use of technology extending through the post-COVID-19 era and in the context of the Philippine educational system that is traditionally fashioned by a brick-and-mortar environment. Also, in the practical aspect, this study provides an empirical basis should interventions be designed to further increase the TPK self-efficacy and continuance intention of the teachers in remote education. Specifically, those groups with statistically lower levels of TPK selfefficacy and continuance intention as identified in this study may be strategically targeted. This study further contributes as regards the theoretical connection between the constructs of TPK selfefficacy and continuance intention in the lens of remote education. While the extent of correlation was found modest, it nevertheless offers evidence on the association between these two constructs.

Some limitations, however, should be observed in interpreting the results of this study. The responses in this research were gathered through an online survey. It may be possible that the data were influenced by biases arising from the tendency to report socially desirable responses. While this study also involved a large sample size adequate to generalize, most of the respondents came from a single geographical location, indicating the need to replicate similar studies using stratified samples across different contexts. Lastly, the modest correlation value uncovered in this study suggests other variables that influence the continuance intention of the respondents. Thus, researchers are advised to further explore this area of interest.

Disclosure Statement. No potential conflict of interest is reported by the author.

\section{References}

Alea, L. A., Fabrea, M. F., Roldan, R. D. A., \& Farooqi, A. Z. (2020). Teachers' Covid-19 awareness, distance learning education experiences and perceptions towards institutional readiness and challenges. International Journal of Learning, Teaching and Educational Research, 19(6), 127-144. https://doi.org/10.26803/ijlter.19.6.8

Anoba, J. L. D. \& Cahapay, M. B. (2020). The Readiness of Teachers on Blended Learning Transition for PostCOVID-19 Period: An Assessment Using Parallel Mixed Method. PUPIL: International Journal of Teaching, Education and Learning, 4(2), 295-316. https://doi.org/10.20319/pijtel.2020.42.295316

Bai, B., Wang, J., \& Chai, C. S. (2019). Understanding Hong Kong primary school English teachers' continuance intention to teach with ICT. Computer Assisted Language Learning, 34(4), 528-551. https:/ / doi.org/10.1080/09588221.2019.1627459

Black, M. R. (2019). A comparative analysis of teacher efficacy scores of online business faculty based on educational background [Doctoral dissertation, Liberty University]. https://core.ac.uk/download/pdf/225131983.pdf

Butucha, K. (2013). Gender and school type differences in self-efficacy in teaching. Sky Journal of Educational Research, 1(4), 23-31.

Cassidy, S., \& Eachus, P. (2002). Developing the computer user self-efficacy (CUSE) scale: Investigating the relationship between computer self-efficacy, gender and experience with computers. Journal of Educational Computing Research, 26(2), 133-153. https:// doi.org/10.2190/jgjr-0kvl-hrf7-genv

Chauhan, S., Goyal, S., Bhardwaj, A. K., \& Sergi, B. S. (2021). Examining continuance intention in business schools with digital classroom methods during COVID-19: a comparative study of India and Italy. Behaviour \& Information Technology, 1-24. https:/ / doi.org/10.1080/0144929x.2021.1892191

Chiu, C. M., \& Wang, E. T. (2008). Understanding Web-based learning continuance intention: The role of subjective task value. Information \& Management, 45(3), 194-201. https:/ / doi.org/10.1016/j.im.2008.02.003

Chu, R. J. C. (2010). How family support and Internet self-efficacy influence the effects of e-learning among higher aged adults-Analyses of gender and age differences. Computers $\mathcal{E}$ Education, 55(1), 255-264. https:// doi.org/10.1016/j.compedu.2010.01.011

Cicha, K., Rizun, M., Rutecka, P., \& Strzelecki, A. (2021). COVID-19 and higher education: first-year students' expectations toward distance learning. Sustainability, 13(4), 1889. https://doi.org/10.3390/su13041889 
Cui, Y. (2021, January). The influence of quality factors on the satisfaction and continuance intention of chinese college students' online learning during the COVID-19 epidemic. In K.-C. Chen (Ed.), 12th International Conference on E-Education, E-Business, E-Management, and E-Learning (pp. 145-150). ICPS. https://doi.org/10.1145/3450148.3450168

Davis, F.D. (1989). Perceived usefulness, perceived ease of use and user acceptance of information technology. MIS Quarterly, 13(3), 319-339. https:// doi.org/10.2307/249008

Deci, E. L., \& Ryan, R. M. (1980). Self-determination theory: When mind mediates behavior. The Journal of Mind and Behavior, 33-43. https://www.jstor.org/stable/43852807

Dong, Y., Xu, C., Chai, C.S., \& Zhai, X. (2020). Exploring the Structural Relationship among Teachers' Technostress, Technological Pedagogical Content Knowledge (TPACK) Computer Self-Efficacy and School Support. The Asia-Pacific Education Researcher, 29(2), 147-157. https://doi.org/10.1007/s40299-01900461-5

Dotong, C.I., De Castro, E.L., Dolot, J.A., \& Prenda, M.T.B. (2016). Barriers for educational technology integration in contemporary classroom environment. Asia Pacific Journal of Education, Arts and Sciences, $3(2), 13-20$.

Durak, H.Y. (2019). Modeling of relations between K-12 teachers' TPACK levels and their technology integration self-efficacy, technology literacy levels, attitudes toward technology and usage objectives of social networks. Interactive Learning Environments, 1-27. https:/ / doi.org/10.1080/10494820.2019.1619591

Guo, Z., Xiao, L., Van Toorn, C., Lai, Y., \& Seo, C. (2016). Promoting online learners' continuance intention: An integrated flow framework. Information $\mathcal{E}$ Management, 53(2), 279-295. https:// doi.org/10.1016/j.im.2015.10.010

Han, M., Wu, J., Wang, Y., \& Hong, M. (2018). A model and empirical study on the user's continuance intention in online China brand communities based on customer-perceived benefits. Journal of Open Innovation: Technology, Market, and Complexity, 4(4), 46. https://doi.org/10.3390/joitmc4040046

Hatlevik, O. E., Throndsen, I., Loi, M., \& Gudmundsdottir, G. B. (2018). Students' ICT self-efficacy and computer and information literacy: Determinants and relationships. Computers $\mathcal{E}$ Education, 118, 107-119. https://doi.org/10.1016/j.compedu.2017.11.011

Hayashi, A., Chen, C., Ryan, T., \& Wu, J. (2004). The role of social presence and moderating role of computer self efficacy in predicting the continuance usage of e-learning systems. Journal of Information Systems Education, 15(2), 139-154.

Horvitz, B., Beach, A., Anderson, M., \& Xia, J. (2014). Examination of Faculty Self-efficacy Related to Online Teaching. Innovative Higher Education, 40(4), 305-316. https:// doi.org/10.1007/s10755-014-9316-1

Huang, C. (2013). Gender differences in academic self-efficacy: A meta-analysis. European Journal of Psychology of Education, 28(1), 1-35. https://doi.org/10.1007/s10212-011-0097-y

International Association of Universities. (2020, April 25). COVID-19: Higher education challenges and responses [Report]. https://www.iau-aiu.net/Covid-19-Higher-Education- challenges-and-responses

Iivari, N., Sharma, S., \& Ventä-Olkkonen, L. (2020). Digital transformation of everyday life-How COVID-19 pandemic transformed the basic education of the young generation and why information management research should care?. International Journal of Information Management, 55, 102183. https:/ / doi.org/10.1016/j.ijinfomgt.2020.102183

Ismail, N. Z., Razak, M. R., Zakariah, Z., Alias, N., \& Aziz, M. N. A. (2012). E-learning continuance intention among higher learning institution students' in Malaysia. Procedia-Social and Behavioral Sciences, 67, 409415. https://doi.org/10.1016/j.sbspro.2012.11.345

Jang, S., \& Liu, Y. (2019). Continuance use intention with mobile augmented reality games. Information Technology \& People, 33(1), 37-55. https:// doi.org/10.1108/itp-05-2018-0221

Johnson, R. T. (2020). Beginning Teachers' Technology Integration Self-Efficacy Based on Level of Technology Infusion in the Undergraduate Program [Doctoral dissertation, Liberty University]. https://digitalcommons.liberty.edu/doctoral/2533

Kiray, S.A. (2016). Development of a TPACK self-efficacy scale for preservice science teachers. International Journal of Research in Education and Science, 2(2), 527- 541. https:/ / doi.org/10.21890/ijres.64750

Klassen, R. M., \& Chiu, M. M. (2010). Effects on teachers' self-efficacy and job satisfaction: Teacher gender, years of experience, and job stress. Journal of Educational Psychology, 102(3), 741-756. https://doi.org/10.1037/a0019237

Lai, H. M., Hsiao, Y. L., \& Hsieh, P. J. (2018). The role of motivation, ability, and opportunity in university teachers' continuance use intention for flipped teaching. Computers $\mathcal{E}$ Education, 124, 37-50. https://doi.org/10.1016/j.compedu.2018.05.013 
Lau F. (2017). Chapter 12: Methods for correlational studies. In Lau F, Kuziemsky C (Eds.), Handbook of eHealth Evaluation: An Evidence-based Approach. University of Victoria.

Lavrakas, P. J. (2008). Encyclopedia of survey research methods (Vols. 1-0). Sage Publications, Inc. https://doi.org/10.4135/9781412963947

Lazar, I., Panisoara, I., Panisoara, G., Chirca, R., \& Ursu, A. (2020). Motivation and continuance intention towards online instruction among teachers during the COVID-19 pandemic: The mediating effect of burnout and technostress. International Journal of Environmental Research and Public Health, 17(21), 8002. https:// doi.org/10.3390/ijerph17218002

Lin, T. J. (2021). Exploring the differences in Taiwanese university students' online learning task value, goal orientation, and self-efficacy before and after the COVID-19 outbreak. The Asia-Pacific Education Researcher, 30(3), 191-203. https:// doi.org/10.1007/s40299-021-00553-1

Lin, K. M., Chen, N. S., \& Fang, K. (2011) Understanding e- learning continuance intention: A negative critical incidents perspective. Behaviour $\mathcal{E}$ Information Technology, 30(1), 77-89. https://doi.org/10.1080/01449291003752948

Lin, X., Featherman, M., \& Sarker, S. (2017). Understanding factors affecting users' social networking site continuance: A gender difference perspective. Information $\mathcal{E}$ Management, 54(3), 383-395. https://doi.org/10.1016/j.im.2016.09.004

Luz, J. M. (2020, August 01). 3 case studies: How ready are Philippine schools for distance learning? Rappler. Retrieved from https://www.rappler.com/nation/ase-studies-how-ready-are-philippine-schools-fordistance-learning

Mallillin, L. L. D., Mendoza, L. C., Mallillin, J. B., Felix, R. C., \& Lipayon, I. C. (2020). Implementation and readiness of online learning pedagogy: a transition to COVID 19 pandemic. European Journal of Open Education and E-learning Studies, 5(2), 71-90. https://doi.org/10.46827/ejoe.v5i2.3321

Ma, K., Chutiyami, M., Zhang, Y., \& Nicoll, S. (2021). Online teaching self-efficacy during COVID-19: Changes, its associated factors and moderators. Education and Information Technologies, 1-23. https://doi.org/10.1007/s10639-021-10486-3

Mo, C. Y., Hsieh, T. H., Lin, C. L., Jin, Y. Q., \& Su, Y. S. (2021). Exploring the critical factors, the online learning continuance usage during COVID-19 pandemic. Sustainability, 13(10), 5471. https:// doi.org/10.3390/su13105471

Nikou, S. A. (2021). Web-based videoconferencing for teaching online: Continuance intention to use in the post-COVID-19 period. Interaction Design and Architecture, 47, 123-143.

Penrose, A., Perry, C., \& Ball, I. (2007). Emotional intelligence and teacher self efficacy: The contribution of teacher status and length of experience. Issues in Educational Research, 17(1), 107-126.

Robinia, K. A. (2008). online teaching self-efficacy of nurse faculty teaching in public, accredited nursing programs in the state of Michigan [Doctoral Dissertation, Western Michigan University] https://scholarworks.wmich.edu/dissertations/811

Roca, J. C., \& Gagné, M. (2008). Understanding e-learning continuance intention in the workplace: A selfdetermination theory perspective. Computers in Human Behavior, 24(4), 1585-1604. https://doi.org/10.1016/j.chb.2007.06.001

Rohatgi, A., Scherer, R., Hatlevik, O. E. (2016). The role of ICT self-efficacy for students' ICT use and their achievement in a computer and information literacy test. Computers \& Education, 102, 103-116. https://doi.org/10.1016/j.chb.2017.01.034

Santi, E. A., Gorghiu, G., \& Pribeanu, C. (2020). Teachers' perceived self-efficacy for mobile teaching and learning. Romanian Journal for Multidimensional Education/Revista Romaneasca pentru Educatie Multidimensionala, 12. https:// doi.org/10.18662/rrem/12.1sup2/259

Sousa, V. D., Driessnack, M., \& Mendes, I. A. C. (2007). An overview of research designs relevant to nursing: Part 1: quantitative research designs. Revista Latino-Americana de Enfermagem, 15(3), 502-507. https:/ / dx.doi.org/10.1590/S0104-11692007000300022

Tang, J. T. E., Tang, T. I., \& Chiang, C. H. (2014). Blog learning: effects of users' usefulness and efficiency towards continuance intention. Behaviour \& Information Technology, 33(1), 36-50. https:// doi.org/10.1080/0144929X.2012.687772

Tweed, S. R. (2013). Technology implementation: Teacher age, experience, self-efficacy, and professional development as related to classroom technology integration (Doctoral dissertation). Retrieved from https:/ / eric.ed.gov/?id=ED554884

United Nations (2021). Pandemic disruption to learning is an opportunity to reimagine, revitalize education. UN News. Retrieved from https://news.un.org/en/story/2021/01/1082792 
Wang, L. Y. K., Lew, S. L., Lau, S. H., \& Leow, M. C. (2019). Usability factors predicting continuance of intention to use cloud e-learning application. Heliyon, 5(6), e01788. https://doi.org/10.1016/j.heliyon.2019.e01788

Wang, T., Lin, C. L., \& Su, Y. S. (2021). Continuance intention of university students and online learning during the COVID-19 pandemic: a modified expectation confirmation model perspective. Sustainability, 13(8), 4586. https://doi.org/10.3390/su13084586

World Bank (2020, June 18). COVID-19 Could lead to permanent loss in learning and trillions of dollars in lost earnings. https://www.worldbank.org/en/news/press-release/2020/06/18/covid-19-could-lead-topermanent-loss-in-learning-and-trillions-of-dollars-in-lost-earnings

Yang, C. (2021). Online teaching self-efficacy, social-emotional learning (SEL) competencies, and compassion fatigue among educators during the COVID-19 pandemic. School Psychology Review, 1-14. https://doi.org/10.1080/2372966x.2021.1903815 